\title{
VIOLENCIA Y MUJER. LA INTERVENCIÓN DE CRISIS CON MUJERES MALTRATADAS Y SUS HIJOS
}

\author{
MARÍA JOSÉ ESCARTÍN CAPARRÓS \\ Profesora titular de Trabajo Social \\ Universidad de Alicante.
}

\begin{abstract}
La extorsión, el insulto, la amenaza, el coscorrón, la bofetada, la paliza, el azote, el cuarto oscuro, la ducha helada, el ayuno obligatorio, la comida obligatoria, la prohibición de salir, la prohibición de decir lo que se piensa, la prohibición de hacer lo que se siente y la humillación pública son algunos de los métodos de penitencia y tortura tradicionales en la vida de familia. Para castigo de la desobediencia y escarmiento de la libertad, la tradición familiar perpetúa una cultura del terror que humilla a la mujer, enseña a los hijos a mentir y contagia la peste del miedo.

- Los derechos humanos tendrían que empezar por casa-.
\end{abstract}

Eduardo Galeano, El Libro de los Abrazos.

\section{RESUMEN}

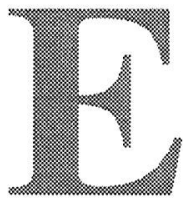

1 presente artículo trata acerca de la violencia a que son sometidas muchas mujeres en el ámbito doméstico por su pareja abusando de la situación de poder que en nuestra sociedad todavía tienen los varones. Estas situaciones continuadas de malos tratos y abusos físicos tienen consecuencias nefastas para las mujeres y los hijos, a veces hasta llegar a la muerte, en los casos más extremos, pero, desafortunadamente no poco frecuentes. Las mujeres que pueden llegar a vivir estos acontecimientos como una crisis y reaccionar pidiendo ayuda son las que pueden llegar a salvarse. Presentamos unas indicaciones para el tratamiento de las 
mujeres que piden ayuda, especialmente en lo que se refiere a los primeros contactos.

\section{LA VIOLENCIA EN LA PAREJA}

La familia es un sistema que permite al hombre mantener un estado de equilibrio y también desarrollar los mecanismos que le permiten madurar. Pero el equilibrio puede estar amenazado, desde el interior del sistema, desde el exterior o de forma combinada.

Si los mecanismos habituales que sirven para mantener el equilibrio fracasan y la tensión no se alivia, se quiebra la atmósfera interior de bienestar y de control, se quiebra el Yo y el hombre se vuelve violento.

Aunque, evidentemente, esto puede ocurrir dentro de la familia a todos sus miembros, y encontramos hechos de malostratos de la mujer hacia el hombre o de los hijos hacia los padres, vamos a ocuparnos de un tipo de violencia estadísticamente mas importante: el de la violencia del hombre hacia la mujer, agravado por el hecho de la posición de sumisión y opresión que aún en nuestra sociedad ocupa ésta.

El mundo privado de la familia parece ser uno de los lugares idóneos para la expresión de la agresividad que las frustraciones personales o cualquier otra causa generadora de ira provoca en el hombre, expresión que se manifiesta habitualmente sobre aquellos objetos considerados socialmente, desde una perspectiva tradicional, como legítimos y propios: la mujer y los hijos. Ahí rigen normas de permisividad y tolerancia sobre conductas que en el mundo exterior son reprimidas.

Esta situación está -todavía hoy-mantenida por la ideología patriarcal que subyace en nuestra sociedad y cuya idea predominante gira alrededor de la suposición básica de la inferioridad de la mujer y de la superioridad del varón, lo que lleva a plantear diferencias entre los sexos como una diferencia jerárquica. En esa jerarquía, el varón se instala en el nivel superior y, desde allí, detenta el poder, ejerce el control y perpetúa un orden que contribuye a consolidar la opresión de la mujer. Esta ideología promueve una división sexual del trabajo, por la cual los hombres son asignados a la producción y al ámbito público, mientras que las mujeres lo son a la reproducción y al ámbito doméstico. Esta jerarquización se expresa, en todas las aéreas del funcionamiento social, bajo la forma de opresión a la mujer: sexual, económi$\mathrm{ca}$, intelectual, política, religiosa, psicológica, afectiva... ${ }^{1}$

La violencia doméstica, en la mayoría de los países del mundo, es la causa de la mayoría de los ataques violentos hacia las mujeres, cues-

I Coria, C. El sexo oculto del dinero, Argot, Barcelona, 1987, p. 73. 
tión agravada por el hecho de la «privacidad» del domicilio familiar y lo que ocurre dentro de él, lo cual, de alguna manera, justifica la pasividad de familiares, amigos y la sociedad en general.

\section{APROXIMACION AL CONCEPTO DE MALTRATO}

«El concepto de maltrato tiene un significado más amplio que el acotado por el maltrato físico: es una acción negativa, una agresión que, por canales de expresión psíquicos o físicos, produce daño y perturba la libertad del otro» ${ }^{2}$.

Por tanto, cuando hablamos de maltrato, no nos referimos solamente a golpes y palizas, es decir, el maltrato físico, sino que estaríamos hablando también del maltrato psicológico y las agresiones sexuales.

Es posible detectar el maltrato físico, pero el psíquico no responde a una norma institucionalizada, es más ambiguo, a pesar de su mayor frecuencia.

La agresión violenta, si bien no es valorada positivamente, es un indicador de masculinidad, mientras que la capacidad de «agresión racional o psicológica» adjudicada a la naturaleza femenina (también desde el discurso femenino): la mujer provoca «sutilmente» la reacción violenta del hombre. Esta pauta de comunicación estereotipada, hace que en el ámbito doméstico, la violencia se vea como algo «normal».

La agresión está en relación con la frustración. En este sentido, Agnes Heller ${ }^{3}$ explica: «la gravedad no se dirige inmediatamente contra el que provoca la frustración (...) sino que puede manifestarse hacia personas que de ningún modo han frustrado a la persona en cuestión...» Y en palabras de Haimovich ${ }^{4}$ : «el hombre restituye su autoridad perdida» en el único espacio en el cual puede ejercer su poder: el ámbito doméstico (...) sobre los objetivos considerados «legítimos» socialmente (...) percepción del mundo privado como ámbito regido por normas de tolerancia, de permisividad sobre conductas que en el mundo exterior se inhiben. Dentro de este orden se articula el sentimiento de propiedad sobre la esposa. Cuando esto se vive amenazado por la expresión de la individualidad, del conflicto por parte de la mujer, percibida en ese instante como «otro» y no como una prolongación del propio Yo, se realiza una descarga agresiva para restituir la propiedad.

Este hecho de la violencia doméstica contra las mujeres no es, por otra parte, un hecho aislado, producido en un país determinado o resul-

2 Haimovich, P. El Maltrato y la Agresión contra la Mujer: Ideología y representaciones sociales. Instituto de la Mujer, Madrid, 1989, p. 15.

3 Heller, A., Agresividad y Carácter, Ed. Península, Barcelona, 1980, p. 78.

4 Haimovich, P. op. cit., p. 27. 
tado de una determinada cultura o religión. Es decir, tristemente, el problema no queda limitado a la acción del integrismo -caso, por ejemplo, de los países árabes-o de la política china de marginar a hijas, sino que es un hecho universal y que se ha venido produciendo a lo largo de toda la historia y en todas las civilizaciones.

En nuestro país, por ejemplo, del resumen de actividades de la Asociación de Mujeres Separadas y Divorciadas, se desprende que desde 1973, año de su fundación, hasta 1990 atendió y asesoró a noventa y dos mil mujeres con serios problemas en su matrimonio, de las cuales, más de ochenta y cinco mil habían sufrido algún tipo de malos tratos. ${ }^{5}$

\section{CARACTERÍSTICAS DE LAS MUJERES MALTRATADAS}

Los malos tratos se producen en todas las clases sociales o estamentos económicos. Aunque es evidente que, si extraemos datos de las Comisarías o de los Centros de Salud, podemos encontrar principalmente mujeres de situación modesta y las más desamparadas suelen ser las «amas de casa».

En general, cualquier profundización en los casos de malos tratos, nos llevan a los siguientes rasgos:

- Dependencia económica.

- Desconocimiento de los derechos.

- Dependencia psicológica.

- Actitud infantil ante la vida.

- Inmadurez, inexperiencia.

- Antecedentes familiares de malos tratos.

- Atracción por el marido violento; esto se debe a:

- frecuencia y grado de la conducta abusiva;

- el hecho de que ella fue víctima de malos tratos en su infancia;

- el grado de poder-dominación del hombre y los recursos de la mujer.

- Baja autoestima, acompañada de sentimientos de vergüenza, miedo y, a veces, verdadero cariño hacia el marido agresor.

\section{INDICACIONES DE TRATAMIENTO CUANDO SE PRODUCE LA CRISIS}

Las mujeres maltratadas generalmente están sometidas a una prolongada situación de abuso por parte de su pareja, por lo que pasan por

5 Caño, X., Maltratadas. El infierno de la violencia sobre las mujeres, temas'de hoy, col. España Hoy, Madrid, 1995, p. 106. 
un dilatado período de estrés y trauma del cual resulta una continua pérdida de energía. La mujer está en una situación de vulnerabilidad y, cuando es muy golpeada u ocurre otro hecho coincidente (por ejemplo, el abusador comienza también a lastimar a los niños), la mujer cae en un verdadero estado de crisis.

Siguiendo a Bard y Ellison ${ }^{6}$, una crisis es una reacción subjetiva a una experiencia de vida estresante que afecta la estabilidad emocional de la persona y cuya capacidad de pensar y actuar normalmente queda seriamente dañada. Sin embargo, también es cierto que en una situación de crisis, el desorden emocional y la angustia son tan elevados que las personas se sienten impelidas a actuar para salir de esa situación que tan elevado coste de bienestar conlleva. Pero hay que tener en cuenta que la intervención ha de ser rápida, pues estas mujeres, a menudo, sólo están motivadas para cambiar durante el período de crisis. De acuerdo con Caplan, Aguilera y Messik, ${ }^{7}$ la mujer entra en un estado de crisis cuando concurren las siguientes condiciones:

1. La víctima experimenta un incidente precipitante.

2. El incidente es percibido por la mujer como amenazador para su seguridad o la de sus hijos y tiene como resultante la intensificación de la tensión y de la desolación.

3. La mujer maltratada intenta resolver la situación usando sus mecanismos habituales de conducta.

4. El desorden emocional aumenta y la víctima siente que el dolor y la angustia son insoportables.

Es en este punto cuando algunas mujeres quieren experimentar un cambio y piden asesoramiento. El énfasis en el asesoramiento estriba entonces en identificar el factor precipitante y las reacciones cognitivas y emocionales de la mujer.

Los tres acontecimientos precipitantes más corrientes son: a) un incidente de golpes con vejaciones psíquicas; b) una vejación grave infringida al hijo de la víctima y c) un deterioro de la audición, de la vista o todo junto como consecuencia de los apaleamientos. A menudo, el acontecimiento precipitante es percibido por la mujer como el incidente final o «la gota que colma el vaso» en una larga historia de violencia.

Un efectivo tratamiento requiere la comprensión de la teoría y las técnicas de crisis. Para ayudar a una persona en situación de crisis se precisa fundamentalmente una gran sensibilidad y desarrollar activamente habilidades de escucha empática.

- Bard, M. y Ellison, K., cit. en Roberts, A. Crisis Intervention Handbook, Wadsworth Inc,, 1990, Belmont., p. 8).

7 Caplan, G., Principles of Preventive Psychiatry, 1964, N. York, Basic Books. Aguilera, D.C., Messick, J.M., Crisis Intervention: Theory and Methodology, 1984, St. Louis, C.V. Mosby. 
También hay que discriminar la urgencia de la demanda de la mujer, indagando cuestiones tales como:

- ¿Está ud. o sus hijos en peligro en este momento?.

- ¿Está el abusador en su casa ahora?.

- ¿Quiere que llame a la policía?.

- ¿Quiere abandonar a su marido y sentirse segura?.

- ¿Necesita atención médica?.

Aclarar esto es especialmente importante, sobre todo si la demanda se hace por teléfono (p.e. a través del Teléfono de la Esperanza, el del Instituto de la Mujer, etc.).

La intervención con estas mujeres ha de hacerse de forma ordenada, estructurada y humanística y tener en cuenta que, a consecuencia de una adecuada intervención, muchas mujeres son capaces de conseguir el control de sus vidas y tomar sus propias decisiones. En este sentido, sería aconsejable una metodología de intervención a nivel individual que disminuyera el miedo y la angustia de la mujer y, a continuación, o de forma combinada, un tratamiento de grupo con otras mujeres que han pasado por las mismas experiencias, en orden a reforzar los logros conseguidos por la víctima.

La metodología de intervención que se propone, desde el punto de vista individual, constaría de tres pasos básicos:

A) Realización del contacto.

B) Identificación del problema.

C) Trabajar con el problema

La siguiente guía de entrevista fue elaborada por Jones ${ }^{8}(1968)$ y es muy utilizada en programas con víctimas de abusos y malos tratos en centros de Estados Unidos y puede ser útil para el primer contacto con las mujeres que se deciden a solicitar ayuda y va encaminada a lograr la confianza de la mujer en el trabajador social y a poder hablar de su problema de una manera más racional y objetiva, intentando calmar el desorden emocional y vencer el miedo y la inseguridad.

\section{A. Realización del contacto}

1. Presentación: nombre, rol y objetivo del profesional.

2. Si es una llamada telefónica, preguntarle a la víctima si se siente segura y protegida en ese momento.

3. Preguntarle cómo le gustaría que el profesional se dirija a ella: nombre, apellido, diminutivo; esto ayuda a los clientes a recuperar el control. 
4. Recoger datos de la cliente; esto ayuda a romper el hielo y permite que ambas - mujer y trabajadora social- se conozcan y se desarrolle la confianza.

5. Preguntarle a la mujer si tiene médico o si está tomando alguna medicación.

6. Identificar los sentimientos de la víctima e indagar su percepción acerca de lo sucedido.

\section{B. Identificación del problema.}

1. Pedir a la cliente que describa brevemente lo sucedido.

2. Animar a la cliente a que hable del aquí y ahora.

3. Preguntarle qué es lo que más le angustia de su problema.

4. Preguntarle si ha tenido que enfrentarse con un problema similar antes de ahora y, si es así, cómo lo ha manejado.

5. Preguntarle si ha hablado antes con alguien y si, al hacerlo ahora, se siente más fuerte.

6. Revisar con ella lo que se considere como problema primario.

\section{Trabajar con el problema.}

1. ¿Qué hace la víctima cuando sucede?.

2. ¿Cuál es su necesidad más importante?.

3. Explorar lo que ella considera la mejor solución.

4. Descubrir lo que ella está dispuesta a hacer para enfrentarse a su problema.

5. Ayudarla a formular un plan de acción (recursos, actividades, tiempo).

6. Concertar nueva cita.

Una vez que la mujer y sus hijos se encuentran a salvo del agresor (p.e., en una Casa para Mujeres Maltratadas u otro tipo de recurso similar) y el peligro de ulteriores agresiones ha desaparecido, es el momento adecuado para iniciar el tratamiento de grupo.

Rhodes y Zelman ${ }^{9}$ han diseñado un modelo de terapia de grupo desde el modelo de crisis que sirve tanto a las madres como a sus hijos, y los objetivos van orientados en dos direcciones: a) reducir los sentimientos de aislamiento y soledad de las personas en crisis y $b$ ) fortalecer las relaciones entre madres e hijos. La base de estos grupos es, evidentemente, las experiencias compartidas por las mujeres en similares situaciones y los apoyos y recursos que se presten unas a otras.

9 Rhodes, R.M., Zelman, A.B., An Ongoing Multi-Family Group in a Women's Shelter, 1986, N. York, Springer, p. 120. 


\section{CONCLUSIONES}

Debido al alto número de mujeres maltratadas en el ámbito doméstico por sus propios padres o maridos, de una manera constante y obsesiva, la sociedad debiera prestar atención inmediata a este fenómeno y arbitrar los recursos adecuados desde todos los puntos de vista: a nivel penal, con actuaciones contundentes por parte de la policía y de la justicia; a nivel social, con suficiente número de recursos y profesionales para dar respuestas rápidas a las demandas y evitar consecuencias más dramáticas como muertes y lesiones permanentes; pero, también, desde el punto de vista cultural, ya que la mujer no es una posesión del varón con la que puede hacer lo que quiera y, en ocasiones, las mujeres no encuentran ayuda ni en su propia familia.

Un tratamiento de crisis en los casos que la mujer se decide a pedir ayuda es sumamente útil, ya que es el momento en que la motivación para cambiar su situación y la de sus hijos es más alta y, por lo tanto, está más capacitada para movilizarse, siendo imprescindible, entonces, ofrecerle la oportunidad y los medios para conseguirlo. 